\title{
Neighbourhood differences in objectively measured physical activity, sedentary time and body mass index
}

\author{
Stephanie A. Prince ${ }^{1,2^{*}}$, Mark S. Tremblay ${ }^{2,3,4}$, Denis Prud'homme ${ }^{3}$, Rachel Colley ${ }^{2,4}$, \\ Michael Sawada ${ }^{5}$, Elizabeth Kristjansson ${ }^{6}$
}

\footnotetext{
${ }^{1}$ Population Health PhD Program, University of Ottawa, Ottawa, Canada; ${ }^{*}$ Corresponding Author: s.prince.ware@gmail.com

${ }^{2}$ Healthy Active Living and Obesity Research Group, Children's Hospital of Eastern Ontario, Ottawa, Canada;

${ }^{3}$ Faculty of Health Sciences, University of Ottawa, Ottawa, Canada;

${ }^{4}$ Faculty of Medicine, University of Ottawa, Ottawa, Canada;

${ }^{5}$ Laboratory for Applied Geomatics and GIS Science (LAGGISS), Department of Geography, University of Ottawa, Ottawa, Canada;

${ }^{6}$ School of Psychology, University of Ottawa, Ottawa, Canada.
}

Received 9 September 2011, revised 13 October 2011; accepted 23 October 2011.

\section{ABSTRACT}

Background: There is limited Canadian research examining whether directly measured physical activity (PA) and body mass index (BMI) differ between neighbourhoods with different objectively measured socioeconomic (SES) and recreation (REC) environments. Purpose: To determine whether mean adult PA levels, sedentary time and BMls were different across four neighbourhoods with contrasting SES and REC environments in Ottawa, Canada. Methods: This study employed a crosssectional design to collect pilot data of objectively measured height, weight and PA (using accelerometry) and self-reported covariates in 113 adults ( $\geq 18$ years). Four contrasting neighbourhoods (high REC/high SES, high REC/low SES, low REC/high SES, and low REC/low SES) were selected based on data collected as part of the Ottawa Neighbourhood Study. Analysis of covariance and logistic regression were used to perform neighbourhood comparisons for PA, sedentary time and BMI, adjusting for age, sex and household income and possible interactions. Post-hoc comparisons using Tukey's test were performed. Results: Significant neighbourhood-group effects were observed for light intensity PA and sedentary time. Post-hoc tests identified that the low REC/high SES neighbourhood had significantly more minutes of light PA than the low REC/low SES $\left(M_{\text {diff }}=56.05\right.$ minutes $\cdot$ day, Tukey $p=0.01$ ). Unadjusted BMI differed between the four neighbourhoods, but the differences were not significant after controlling for age, sex and household income. Conclusions: This study demonstrates that light PA and sedentary time differ between neighbourhoods of varying REC and SES environments after controlling for differences in age, sex and household income. Findings also suggest that other area-level factors may explain these neighbourhood differences.

Keywords: Physical Activity; Sedentary Time; Obesity; Neighbourhood; Environment

\section{INTRODUCTION}

Despite the benefits of daily physical activity (PA) and a healthy body weight for the prevention of several chronic diseases and premature mortality, most adult Canadians continue to fall short of PA recommendations and are overweight or obese [1-3]. Evidence suggests a link may exist between the recreation and social environments and an individual's likelihood of being physically active or overweight/obese [4-6]. Historically, the majority of research in this area has focused on perceived access to environments (e.g. what an individual feels they have access to or what they perceive their environment to be like) rather than objective measures of their built and socioeconomic environment (e.g. the number of facilities in their neighbourhood or average income levels) [7]. Results from objectively measured studies are mixed, but generally report positive associations between greater access to recreation environments and PA while lower access tends to be associated with greater odds of overweight and obesity [7-10]. Importantly, fewer studies have linked objectively measured environments to directly measured PA, sedentary time and body mass index (BMI) and even fewer have done 
so in a Canadian context $[7,10]$. While some research has examined the independent relationship of either the recreation or social environments with $\mathrm{PA}$ and $\mathrm{BMI}$, less is known about the possible synergistic effects of these two determinants. Research looking at environmental factors associated with light PA and sedentary time is emerging, but remains limited. In Canada, availability of recreation resources may be lower among neighbourhoods of lower socioeconomic status (SES) and, as such, an area's SES may affect the relationship of the recreation environment on PA [11-14].

In light of the possible effect of neighbourhood SES on the relationship between the recreation environment and PA and BMI, and current gaps in the literature, the main aim of this study was to compare objectively measured mean PA levels, sedentary behaviour and BMIs across four neighbourhoods with contrasting SES and recreation environments in adults living in Ottawa, Canada. Our hypothesis was that the neighbourhood with the fewest recreation resources and lowest neighbourhood SES would have the lowest levels of PA, greatest amounts of sedentary time and largest BMIs.

\section{METHODS}

This study was carried out in Ottawa, a large Canadian city with a regional population of approximately 1.2 million residents. Mean minutes of directly measured light, moderate and vigorous PA, sedentary time, step counts, and BMI were compared between participants living in four pre-selected, contrasting neighbourhoods characterized by their objectively measured SES and recreation (REC) environments. The study received ethical approval from the University of Ottawa's Health Science Research Ethics Board and the Children's Hospital of Eastern Ontario (CHEO) Research Ethics Board.

\subsection{Participants}

The study population includes 113 adults ( $\geq 18$ years) with complete PA and BMI data. Participants were recruited through community newsletters, bulletin board posters, mailbox flyers, mail postcards, and word of mouth. Respondents were required to speak and read English or French, agree to wear an accelerometer for a minimum of five weekdays and two weekend days, have their heights and weights measured, and live within the boundaries of one of the study neighbourhoods as determined by their residential address. One adult per household was eligible to participate. Participants were provided with a \$20 honorarium and a PA profile following participation in the study. Study measurement sessions took place in public facilities where written informed consent was obtained, height and weight mea- surements were taken and instructions for accelerometer use were explained. Participants were provided with an Actical ${ }^{\circledR}$ accelerometer (Phillips-Respironics, Oregon, USA), an instruction booklet/questionnaire, and a prepaid addressed envelope to return the study materials and accelerometer.

\subsection{Study Neighbourhoods}

Participants were recruited from four neighbourhoods within the City of Ottawa. The neighbourhood boundaries were defined by the Ottawa Neighbourhood Study (ONS; www.neighbourhoodstudy.ca), a large study examining associations between neighbourhood characteristics and health outcomes. Figure 1 provides a map of the ONS neighbourhoods with the four chosen study neighbourhoods highlighted. The neighbourhoods were chosen to represent four contrasting areas based on REC and SES environments. The neighbourhoods are as follows: 1) high REC/high SES; 2) high REC/low SES; 3) low REC/high SES; and 4) low REC/low SES.

\subsection{Ottawa Neighbourhood Study (ONS)}

In the ONS, neighbourhoods were defined based on natural boundaries, similarity in SES and demographics, Ottawa Multiple Listing Services maps, and participatory mapping feedback from community members and experts [15]. Objectively measured environmental data were collected from 2006 to 2008 using the following data and methods: 1) 2006 Canadian census household data; 2) GIS data from DMTI Spatial Inc., the City of Ottawa, and the National Capital Commission; 3) telephone contact with businesses; 4) web-based research; 5) team knowledge of local resources; and 6) field research and validation. A further in-depth description of methods related to the ONS and its variables is available elsewhere [15].

\subsection{Recreation (REC) Environment}

The REC environment was based on a REC Index that was created using principal components analysis; this served as a measure of the density of facilities for recreation in a neighbourhood [15]. The REC index includes meters of bike and walking paths per person, meters-squared of park space per person, and recreation facilities per thousand people per neighbourhood. The REC index was $t$-scored to represent a mean of 50 with a standard deviation of 10 for comparability across neighbourhoods. Recreational facilities were defined using the North American Industry Classification System - Canada (NAICS) Code 71 and were only included if they were free or had a minimal cost [16]. Green space managed by the City or National Capital Commission was included in the park variable. 


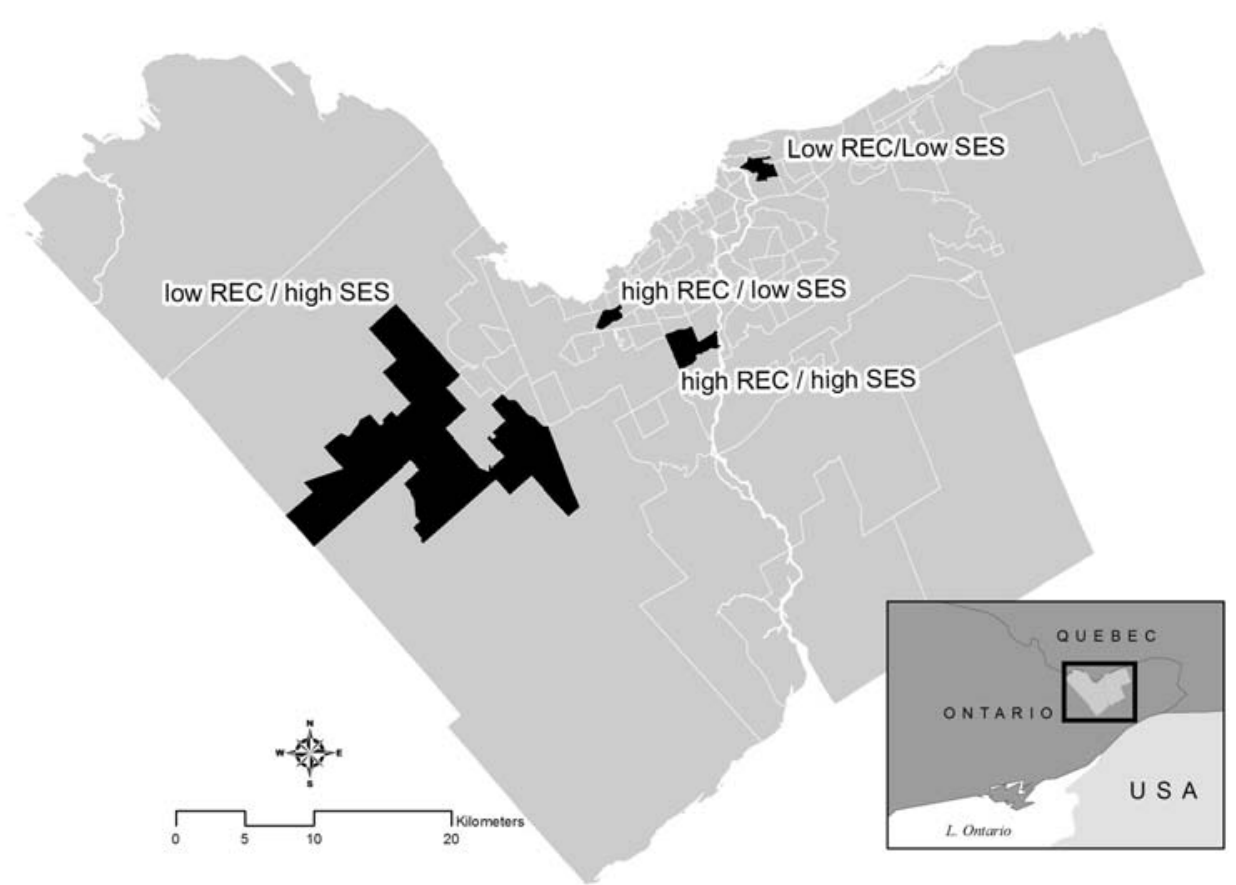

Figure 1. Ottawa neighbourhood study map and the four study neighbourhoods.

\subsection{Socio-Economic (SES) Environment}

The SES environment was assessed using a neighbourhood SES index developed using principal components analysis; it included percent of households below the low-income cut-off (LICO), average household income, percent of unemployed residents, percent of residents with less than a high school education, and percent of single-parent families $[15,17]$. The SES index was $t$-scored to represent a mean of 50 with a standard deviation of 10 .

\subsection{Individual-Level Outcomes}

\subsubsection{Physical Activity (PA) and Sedentary Time}

PA was directly measured using Actical ${ }^{\circledR}$ accelerometers (Phillips-Respironics, Oregon, USA). The accelerometers are small, omni-directional, water resistant movement sensors able to capture all intensities of movement, including sedentary pursuits. The Actical ${ }^{\circledR}$ has been validated to measure PA and step counts in adults $[18,19]$. Participants were asked to wear the accelerometers on their right hip using an elasticized belt during their waking hours for a total of five week days and two weekend days. At midnight after the study meeting, data recording commenced. An epoch length of 60 -seconds was used to capture movement in a count value per minute $(\mathrm{cpm})$. Signals were also translated into steps per minute.

Valid accelerometer results were selected based on guidelines adopted for the data analyses of the Canadian
Health Measures Survey (CHMS) [2,20]. A valid day was defined as $\geq 10$ hours of wear time and participants were required to have $\geq 4$ valid days to be retained for the analyses. Data reduction and analysis was harmonized with the CHMS accelerometry data procedures. Further detail is available elsewhere [2,20].

The accelerometer data were downloaded using the Actical ${ }^{\circledR}$ software program and analysed in SAS. Data are presented as average daily minutes spent in moderate PA, vigorous PA, moderate-to-vigorous PA (MVPA), light activity, and sedentary time, and mean daily steps. PA intensity cut-points used in the identification of activity levels are provided in Table 1. PA was also analysed to assess those meeting current Canadian PA Guidelines and those who obtained an average of 10,000 steps per day versus those that did not [21,22]. If a participant had between four-to-six valid days, their weekly sum was calculated by multiplying the mean daily MVPA by seven.

\subsubsection{Body Mass Index (BMI)}

BMI was calculated using directly measured weight $(\mathrm{kg})$ divided by height squared $\left(\mathrm{m}^{2}\right)$. Standing height was measured using a Seca 214 portable stadiometer (SECA, Hanover MD, USA) and recorded to the nearest centimeter and converted to meters. Weight was measured using a Life Source ProFit scale (A\&D Medical, Milpitas, CA, USA) and recorded to the nearest $0.1 \mathrm{~kg}$. BMI guidelines for adults were used to group individuals into the following categories: underweight $(<18.5$ 
Table 1. Physical activity intensity cut-points for the actical as used by the Canadian Health Measures Survey [2,23,24].

\begin{tabular}{|c|c|c|c|}
\hline Intensity & Metabolic Equivalent (METS) & Example & $\begin{array}{l}\text { Accelerometer count } \\
\text { range }(\mathrm{CPM})\end{array}$ \\
\hline Sedentary & 1 to less than 2 & Car travel, sitting, reclining, standing & Less than $100^{*}$ \\
\hline Light & 2 to less than 3 & Walking less than $3.2 \mathrm{~km} / \mathrm{h}$, light household cleaning, cooking & 100 to less than 1535 \\
\hline Moderate & 3 to less than 6 & $\begin{array}{c}\text { Walking less than } 3.2 \mathrm{~km} / \mathrm{h} \text {, cleaning (vacuuming, washing car), } \\
\text { bicycling for pleasure }\end{array}$ & 1535 to less than 3962 \\
\hline Vigorous & 6 or more & Jogging, competitive team sport participation & 3962 or more \\
\hline
\end{tabular}

CPM - counts per minute *including wear-time zeros.

$\left.\mathrm{kg} \cdot \mathrm{m}^{2}\right)$, normal weight $\left(18.5-24.9 \mathrm{~kg} \cdot \mathrm{m}^{2}\right)$, overweight $\left(25.0-29.9 \mathrm{~kg} \cdot \mathrm{m}^{2}\right)$, and obese $\left(\geq 30 \mathrm{~kg} \cdot \mathrm{m}^{2}\right)$ for descriptive purposes only [25]. BMI was analysed as a continuous outcome.

\subsubsection{Individual-Level Covariates}

Age and sex were forced into the models based on their known associations with PA and BMI. Household income was included based on its significant bivariate association with PA. Information on work, education, marital and smoking status and number of individuals per household were also collected, but were all significantly correlated with household income. To avoid multicollinearity and obtain the most parsimonious model given the sample size, they were not included. Season of data collection was also available; however, it was not significantly associated with either PA or BMI. All covariates were self-reported. Missing information for age or income was imputed based on regression parameter estimates from models using sex, neighbourhood and BMI as predictors. In total, three participants were missing information on age and an additional seven were missing information for income.

Age was included as a continuous measure. Sex was coded as male or female. Household income was considered as a two-level categorical variable that accounts for the number of people in the household and total household income from all sources in the 12 months before the interview: "lower" ( $<\$ 60,000$ for $1-2$ people; $<\$ 80,000$ for $\geq 3$ people) compared to "upper" $(\geq \$ 60,000$ for 1 - 2 people; $\geq \$ 80,000$ for $\geq 3$ people).

\subsection{Statistical Analysis}

All analyses were conducted using SAS version 9.2 (SAS Institute Inc., Cary, NC, USA). Unadjusted descriptive statistics were performed to derive means \pm standard deviations and frequencies of all demographic variables for each neighbourhood. Unadjusted between neighbourhood comparisons were analysed using oneway analysis of variance (ANOVA) for continuous variables and chi-square tests for dichotomous variables. Adjusted between neighbourhood comparisons were performed using analysis of covariance (ANCOVA) for continuous outcomes (using Proc GLM and LSMeans for unequal designs) and logistic regression for binary outcomes (using Proc Logistic and Proc GLM). ANCOVA models allowed for the adjustment of differences in the covariates between neighbourhoods and between subjects in each neighbourhood. Interactions were tested between all covariates and neighbourhoods with no significant interactions observed. Post-hoc Tukey tests were used to perform pairwise comparisons for PA and BMI between the individual neighbourhoods.

\section{RESULTS}

\subsection{Sample Characteristics}

A total of 126 adults ( $\geq 18$ years) were recruited from four neighbourhoods. From this sample, 113 had complete BMI and valid PA data and were used in the analyses. Table 2 provides descriptive characteristics of the participants by neighbourhood.

The participants were reasonably well distributed across the neighbourhoods. Compared to the general $\mathrm{Ca}$ nadian population as assessed by the CHMS, the study participants were leaner than a representative Canadian sample (53\% versus 38\% healthy weight), had similar proportions meeting step-per-day guidelines $(35 \%$ versus $34 \%$ ) and had a greater proportion of individuals meeting MVPA guidelines (31\% versus 15\%) [2,3].

\subsection{Neighbourhood Differences in Physical Activity}

Tables 3 provides comparisons of mean PA levels and proportions meeting the current Canadian PA guidelines [21]. Unadjusted comparisons showed that only mean daily minutes spent in light PA $(p=0.01)$ differed between participants living in the four neighbourhoods; this difference was stronger after adjustment for covariates $(p=0.002)$. Following adjustment, a significant group effect was observed for minutes of sedentary behaviour and light PA. The low REC/high SES neighbourhood had the most minutes spent engaged in light PA with post-hoc tests identifying average minutes were significantly higher than the low REC/low SES neighbourhood $\left(\mathrm{M}_{\text {diff }}=56.05\right.$ minutes $\cdot$ day, Tukey $p=0.01)$.

Following adjustment, mean differences in average 
Table 2. Participant characteristics by neighbourhood $(\mathrm{n}=113)$.

\begin{tabular}{|c|c|c|c|c|}
\hline Characteristics & $\begin{array}{l}\text { High REC/ High } \\
\text { SES }(\mathrm{n}=29)\end{array}$ & $\begin{array}{c}\text { High REC/ } \\
\text { Low SES }(\mathrm{n}=29)\end{array}$ & $\begin{array}{c}\text { Low REC/ } \\
\text { High SES }(\mathrm{n}=23)\end{array}$ & $\begin{array}{c}\text { Low REC/ } \\
\text { Low SES }(n=32)\end{array}$ \\
\hline Male sex, n (\%) & $8(28 \%)$ & $6(21 \%)$ & $4(17 \%)$ & $7(22 \%)$ \\
\hline Age, years & $51.3 \pm 13.7$ & $48.1 \pm 14.1$ & $51.0 \pm 14.1$ & $45.8 \pm 15.0$ \\
\hline \multicolumn{5}{|l|}{ BMI category, $\mathrm{n}(\%)$} \\
\hline Underweight & 0 & $1(3 \%)$ & 0 & 0 \\
\hline Healthy weight & $17(59 \%)$ & $19(66 \%)$ & $7(31 \%)$ & $17(53 \%)$ \\
\hline Overweight & $9(31 \%)$ & $7(24 \%)$ & $12(52 \%)$ & $8(25 \%)$ \\
\hline Obese & $3(10 \%)$ & $2(7 \%)$ & $4(17 \%)$ & $7(22 \%)$ \\
\hline \multicolumn{5}{|l|}{ Household income, $\mathrm{n}(\%)^{*}$} \\
\hline Low & $2(7 \%)$ & $7(24 \%)$ & $7(30 \%)$ & $18(56 \%)$ \\
\hline High & $27(93 \%)$ & $22(93 \%)$ & $16(70 \%)$ & $14(44 \%)$ \\
\hline
\end{tabular}

Data are presented as mean \pm standard deviations unless otherwise stated. REC - recreation index score, SES - socioeconomic status index score. $*$ Mean differences between neighbourhoods based on chi-square or ANOVAs $p<0.001$.

Table 3. Unadjusted and adjusted* average daily and weekly minutes of activity at various levels of intensity, average daily step counts, percent meeting physical activity guidelines, and body mass index by neighbourhood (total $\mathrm{n}=113$ ).

\begin{tabular}{|c|c|c|c|c|c|c|c|c|c|c|}
\hline & \multicolumn{4}{|c|}{ Unadjusted } & \multicolumn{6}{|c|}{ Adjusted* $^{*}$} \\
\hline & $\begin{array}{c}\text { High REC/ } \\
\text { High SES } \\
(n=29)\end{array}$ & $\begin{array}{c}\text { High REC/ } \\
\text { Low SES } \\
(\mathrm{n}=29)\end{array}$ & $\begin{array}{c}\text { Low REC/ } \\
\text { High SES } \\
(n=23)\end{array}$ & $\begin{array}{c}\text { Low REC/ } \\
\text { Low SES } \\
(n=32)\end{array}$ & p-value & $\begin{array}{c}\text { High REC/ } \\
\text { High SES } \\
(n=29)\end{array}$ & $\begin{array}{c}\text { High REC/ } \\
\text { Low SES } \\
(n=29)\end{array}$ & $\begin{array}{l}\text { Low REC/ } \\
\text { High SES } \\
(n=23)\end{array}$ & $\begin{array}{c}\text { Low REC/ } \\
\text { Low SES } \\
(n=32)\end{array}$ & p-value \\
\hline \multicolumn{11}{|l|}{ Activity intensity } \\
\hline Daily minutes of sedentary & $581 \pm 13$ & $602 \pm 13$ & $570 \pm 15$ & $596 \pm 13$ & 0.39 & $591 \pm 16$ & $611 \pm 15$ & $576 \pm 16$ & $599 \pm 13$ & 0.05 \\
\hline Daily minutes of light & $98 \pm 12$ & $87 \pm 12$ & $114 \pm 14$ & $57 \pm 12$ & 0.01 & $88 \pm 14$ & $76 \pm 13$ & $105 \pm 15$ & $49 \pm 12$ & 0.002 \\
\hline Daily minutes of moderate & $15 \pm 4$ & $13 \pm 4$ & $14 \pm 4$ & $20 \pm 4$ & 0.52 & $13 \pm 4$ & $12 \pm 4$ & $13 \pm 5$ & $20 \pm 4$ & 0.82 \\
\hline Daily minutes of vigorous & $4 \pm 1$ & $2 \pm 1$ & $1 \pm 2$ & $3 \pm 1$ & 0.67 & $3 \pm 2$ & $2 \pm 2$ & $1 \pm 2$ & $3 \pm 1$ & 0.24 \\
\hline Daily minutes of MVPA & $19 \pm 4$ & $16 \pm 4$ & $17 \pm 5$ & $23 \pm 4$ & 0.59 & $17 \pm 5$ & $14 \pm 5$ & $15 \pm 5$ & $23 \pm 4$ & 0.82 \\
\hline Weekly minutes of MVPA & $134 \pm 29$ & $112 \pm 29$ & $115 \pm 32$ & $161 \pm 27$ & 0.59 & $118 \pm 35$ & $100 \pm 33$ & $105 \pm 36$ & $159 \pm 30$ & 0.82 \\
\hline Daily step counts & $9446 \pm 682$ & $8518 \pm 682$ & $8596 \pm 766$ & $8413 \pm 649$ & 0.69 & $9208 \pm 815$ & $8227 \pm 768$ & $8436 \pm 841$ & $8217 \pm 696$ & 0.57 \\
\hline $\begin{array}{l}\text { Met weekly MVPA } \\
\text { guidelines, n (\%) }\end{array}$ & $10(34 \%)$ & $9(31 \%)$ & $6(26 \%)$ & $10(31 \%)$ & 0.94 & $8(31 \%)$ & $8(27 \%)$ & $6(22 \%)$ & $12(29 \%)$ & 0.97 \\
\hline $\begin{array}{l}\text { Met daily step guidelines, } \mathrm{n} \\
(\%)\end{array}$ & $12(41 \%)$ & $9(31 \%)$ & $8(35 \%)$ & $9(28 \%)$ & 0.75 & $10(38 \%)$ & $12(27 \%)$ & $6(32 \%)$ & $12(25 \%)$ & 0.34 \\
\hline Body mass index, $\mathrm{kg} \cdot \mathrm{m}^{2}$ & $24.7 \pm 0.8$ & $23.9 \pm 0.8$ & $27.0 \pm 0.9$ & $26.3 \pm 0.8$ & 0.045 & $24.8 \pm 1.0$ & $24.2 \pm 0.9$ & $27.3 \pm 1.0$ & $26.7 \pm 0.8$ & 0.13 \\
\hline
\end{tabular}

All activity is reported in average minutes except for step counts. All results shown as mean \pm standard error. P-value for ANOVA/ANCOVA or chi-square/ logistic regression models. MVPA — moderate-to-vigorous physical activity. *Adjusted for age, sex, household income.

steps per day remained non-significant between neighbourhoods. Furthermore, no significant differences in the proportion of participants meeting the current PA guidelines either by weekly minutes of MVPA or daily step counts were observed. The data were also analysed using percentage of wear time spent in the various levels of PA in order to adjust for the fact that individuals with longer wear times may have subsequently higher minutes of time spent in light and sedentary pursuits. Both the unadjusted and adjusted results were virtually identical to those found for the mean minutes spent at the various PA intensities.

\subsection{Neighbourhood Differences in Body Mass Index (BMI)}

Table 3 provides comparisons of mean BMIs across the four neighbourhoods. Unadjusted comparisons identified that BMI differed between participants living in the four neighbourhoods $(p=0.045)$; this difference lost significance following adjustment $(p=0.13)$. Participants from the two low REC neighbourhoods had the highest average BMIs. Post-hoc tests identified that the low REC/high SES had a higher average BMI than the high REC/low SES neighbourhood, but this difference only approached significance $\left(\mathrm{M}_{\text {diff }}=3.09 \mathrm{~kg} \cdot \mathrm{m}^{2}\right.$, Tukey $p=0.06)$.

\section{DISCUSSION}

This study aimed to investigate whether PA levels, sedentary time and BMI differed between adults living in four Ottawa neighbourhoods with contrasting SES and REC environments. To the best of our knowledge, 
this is the first study to use objective measures of the neighbourhood environment and directly measured PA, sedentary time and BMI in a Canadian population. Furthermore, it is one of the first to look at objective measures of the REC environment, rather than previously examined land-use mix and walkability characteristics, along with SES on directly measured PA levels, sedentary time and BMI. The results support the notion that PA, sedentary time and BMI may differ by factors in the built and social environments and that these differences can be independent of individual-level determinants. The findings do not support our original hypothesis that individuals living in a neighbourhood with a combination of low SES and low availability of recreation facilities would have the lowest amounts of daily PA, greatest amount of sedentary time and highest BMIs.

Interestingly, we found that minutes spent in light PA were significantly greater in the low REC/high SES neighbourhood compared to the low REC/low SES neighbourhood. Research on impacts of the environment on light PA is limited and as mentioned, especially using objective measurements. Research on a small sample of Belgian adults $(\mathrm{n}=120)$ demonstrated that adults living in a 'high walkable' neighbourhood took more steps per day and walked more for transport than those living in a 'low walkable' neighbourhood [26]. Research has also shown that higher mixed-land use is associated with greater levels of PA, possibly due to increased use of active transport [8]. While walkability and mix-land use factors were not used to select our study neighbourhoods, they do offer a reasonable explanation for why light PA was higher in the low REC/high SES neighbourhood.

Area zoning measures were calculated for all four neighbourhoods as a proxy for land use variety. The low REC/low SES neighbourhood had the greatest number of different zonings at 114 compared to the high REC/ high SES neighbourhood with 34 and the high REC/low SES neighbourhood with 30 . The low REC/high SES neighbourhood had 113 different zonings; however, as can be seen in Figure 1, this neighbourhood is one of the largest in Ottawa and naturally would have a greater distribution simply due to its geographical size. The density of the zonings would therefore be lower than in the low REC/low SES neighbourhood.

While walkability was not assessed in the current study, the low REC/high SES neighbourhood is rural compared to the urban and more walkable low REC/low SES neighbourhood. Forms of active transportation are often included as MVPA, therefore, the light PA may be capturing more incidental movements associated with lower intensity activities of daily living such as house and yard work [23]. It is also likely that the low REC/high SES neighbourhood has larger homes and properties, possibly resulting in greater time spent in light household chores. Research has also shown that possible urban-suburban-rural differences exist for PA with rural neighbourhoods more likely to be inactive [27-29]. It is possible that a lower land-mix use and decreased walkablity may provide an explanation for why daily light PA was higher in the low REC/high SES neighbourhood compared to the low REC/low SES neighbourhood. Furthermore, research on neighbourhood SES has also shown that adults living in areas described as lower SES are more likely to use active transport and less likely to use motorized transport [30].

Research on the impact of neighbourhood environments on sedentary behaviour is very limited. Recent work by Van Dyck and colleagues looked at the effect of neighbourhood walkability on accelerometer measured sedentary time in adult men and women from Belgium [31]. Their study identified that contrary to general hypotheses, living in a highly walkable neighbourhood was associated with greater amounts of time spent in sedentary pursuits [31]. Interestingly, neighbourhood SES was not significantly associated with daily inactivity and neighbourhood SES did not modify the relationship between walkability and sedentary time [31]. These findings are similar to those seen in the current study whereby our more urban and walkable neighbourhoods had higher amounts of sedentary time compared to our rural and less walkable (low REC/high SES) neighbourhood.

In another investigation the current authors examined the multilevel associations of the recreation and social environments on self-reported PA and BMI across all of the neighbourhoods in the City of Ottawa using data from the Canadian Community Health Survey (Prince SA, Kristjansson EA, Russell $\mathrm{K}$ et al. Relationships between neighbourhoods, physical activity and obesity: A multilevel analysis of a large Canadian City. Unpublished). Findings from that study indicated that leisure time PA and overweight/obesity were not significantly associated with any recreation resources or social environment variables. In light of these findings and that our neighbourhoods were only selected based on REC and SES, it is likely that other environmental characteristics are influencing PA levels. The relative influence of where people live and work on their PA and BMI may differ by population density characteristics and/or other factors and requires further study. Finally, it is possible that more robust, direct measures may produce fundamentally different results than self-reported measures, and indeed that convention thinking of the influence of built and social environments needs to be challenged and perhaps there are other factors yet to be identified/measured that are impacting upon the environment's 
relationship with PA and BMI.

The present study has limitations that should be recognized. The study's sample size may have been too small to see possible differences and clear trends. It must be noted that recruitment for this study was onerous likely due to the nature of the direct measurement of PA and BMI and the constraints placed on location and times of participant meetings by the Research Ethics Boards. This likely resulted in a biased sample of highly motivated individuals, a common bias in research of this nature. The population was also highly educated $(23 \%$ had a graduate-level degree e.g. masters, doctorate) and affluent ( $70 \%$ had a high household income) and the results are therefore not generalizable. The study should therefore be treated as pilot-level information to challenge other researchers to employ more rigorous measurement methodologies.

It is also important to realize that the accelerometers provide objective measures that remove self-report biases, but they are unable to capture all forms of PA accurately (e.g. weight lifting, rowing, cycling). Participants were also asked to remove the monitors during water activities and as a result swimming was not captured in the PA data.

\section{CONCLUSIONS}

This is the first known Canadian study to examine whether objectively measured neighbourhood recreation and SES environments are associated with levels of directly measured PA and BMI. Results of this study identify that minutes of light intensity PA and sedentary behaviour differ between neighbourhoods of varying recreation and SES environments after controlling for differences in age, sex and income. Findings also suggest that other area-level factors such as mixed-land use and degree of urbanism may explain these neighbourhood differences. Future research into the impact of the neighbourhood on PA and BMI should concomitantly assess multiple aspects of the environment including, but not limited to recreation, amenities, walkability, mixedland use, population density, SES, social support, social cohesion, crime, and perceptions and preferences of the neighbourhood.

\section{ACKNOWLEDGEMENTS}

The authors are grateful to Travis Saunders for his efforts in participant recruitment, data collection and verification and to Dr. Jean-Michelle Billette and Ms. Megan Carter for their statistical and methodological advice. Support for the ONS was provided by the Canadian Institutes of Health Research (funding number 99345), the Champlain Local Health Integration Network, the Ottawa Coalition of Community Health, Resource Centres and United Way Ottawa. Funding for the collection of individual data was provided by a Faculty of Health Sciences and CHEO Partnership Research Grant. S. Prince received funding in support of her doctoral work from the Social Sciences and $\mathrm{Hu}$ manities Research Council of Canada-Doctoral Award, Ontario Ministries of Ontario Graduate Scholarships and a University of Ottawa Excellence Scholarship and Doctoral Research Award.

\section{REFERENCES}

[1] Katzmarzyk, P.T. and Janssen, I. (2004) The economic costs associated with physical inactivity and obesity in Canada: An update. Canadian Journal of Applied Physiology, 29, 90-115. doi:10.1139/h04-008

[2] Colley, R.C., Garriguet, D., Janssen, I., Craig, C.L., Clarke, J. and Tremblay, M.S. (2011) Physical activity of Canadian adults: Accelerometer results from the 2007 to 2009 Canadian Health Measures Survey. Health Reports, 22, 7-14.

[3] Canadian Health Measures Survey: Cycle 1 data tables (2011) Table 35: Distribution of the household population aged 18 to 79 , by body mass index norms based on measured inputs, by age and sex, Canada, 2007 to 2009. Catalogue Number: 82-623-X, Ottawa, Statistics Canada.

[4] Kaczynski, A. and Henderson, K. (2008) Parks and recreation settings and active living: A review of associations with physical activity function and intensity. Journal of Physical Activity and Health, 5, 619-632.

[5] McNeill, L.H., Kreuter, M.W. and Subramanian, S.V. (2006). Social environment and physical activity: A review of concepts and evidence. Social Science \& Medicine, 63, 1011-1022.

doi:10.1016/j.socscimed.2006.03.012

[6] Booth, K.M., Pinkston, M.M. and Poston, W.S. (2005) Obesity and the built environment. Journal of the American Dietetic Association, 105, S110-S117. doi:10.1016/i.jada.2005.02.045

[7] McCormack, G., Giles-Corti, B., Lange, A., Smith, T., Martin, K. and Pikora, T.J. (2004) An update of recent evidence of the relationship between objective and selfreport measures of the physical environment and physical activity behaviours. Journal of Science and Medicine in Sport, 7, 81-92. doi:10.1016/S1440-2440(04)80282-2

[8] Saelens, B.E. and Handy, S.L. (2008) Built environment correlates of walking: A review. Medicine \& Science in Sports \& Exercise, 40, S550-S566. http://dx.doi.org/10.1249/MSS.0b013e31817c67a4

[9] Trost, S.G., Owen, N., Bauman, A.E., Sallis, J.F. and Brown, W. (2002) Correlates of adults' participation in physical activity: review and update. Medicine \& Science in Sports \& Exercise, 34, 1996-2001. doi:10.1097/00005768-200212000-00020

[10] Feng, J., Glass, T.A., Curriero, F.C., Stewart, W.F. and Schwartz, B.S. (2010) The built environment and obesity: A systematic review of the epidemiologic evidence. Health \& Place, 16, 175-190. doi:10.1016/j.healthplace.2009.09.008

[11] Powell, L.M., Slater, S., Chaloupka, F.J. and Harper, D. (2006) Availability of physical activity-related facilities and neighborhood demographic and socioeconomic cha- 
racteristics: A national study. American Journal of Public Health, 96, 1676-1680. doi:10.2105/AJPH.2005.065573

[12] Gilliland, J., Holmes, M., Irwin, J.D. and Tucker, P. (2006) Environmental equity is child's play: mapping public provision of recreation opportunities in urban neighbourhoods. Vulnerable Children and Youth Studies, 1, 256-268. doi:10.1080/17450120600914522

[13] Riva, M., Gauvin, L. and Barnett, T. (2007) Toward the next generation of research into small area effects on health: a synthesis of multilevel investigations published since July 1998. Journal of Epidemiol Community Health, 61, 853-861. doi:10.1136/jech.2006.050740

[14] Wilson, K., Eyles, J., Ellaway, A., Macintyre, S. and Macdonald, L. (2010) Health status and health behaviours in neighbourhoods: A comparison of Glasgow, Scotland and Hamilton, Canada. Health \& Place, 16, 331-338. doi:10.1016/j.healthplace.2009.11.001

[15] Parenteau, M.-P., Sawada, M., Kristjansson, E.A., Calhoun, M., Leclair, S., Labonté, R., et al. (2008) Development of neighborhoods to measure spatial indicators of health. URISA Journal, 20, 43-55.

[16] North American Industry Classification System (NAICS). Catalogue Number: 12-501-XIE, 2007, Ottawa, Statistics Canada.

[17] Low income cut-offs. Catalogue no. 13-551-XIB. 1999. Ottawa, Ontario, Statistics Canada.

[18] Heil, D.P. (2006) Predicting activity energy expenditure using the Actical ${ }^{\circledR}$ activity monitor. Research Quarterly for Exercise \& Sport, 77, 64-80.

[19] Esliger, D.W., Probert, A., Connor-Gorber, S., Bryan, S., Laviolette, M. and Tremblay, M.S. (2007) Validity of the Actical accelerometer step-count function. Medicine \& Science in Sports \& Exercise, 39, 1200-1204. doi:10.1249/mss.0b013e3804ec4e9

[20] Colley, R., Connor-Gorber, S. and Tremblay, M.S. (2010) Quality control and data reduction procedures for accelerometry-derived measures of physical activity. Health Reports, 21, 63-70.

[21] Tremblay, M.S., Warburton, D.E.R., Janssen, I., Paterson, D.H., Latimer, A.E., Rhodes, R.E., et al. (2011) New Canadian Physical Activity Guidelines. Applied Physiology, Nutrition and Metabolism, 36, 36-46. doi:10.1139/H11-009

[22] Tudor-Locke, C., Hatano, Y., Pangrazi, R.P. and Kang, M.
(2008) Revisiting "how many steps are enough?". Medicine \& Science in Sports \& Exercise, 40, S537-S543. doi:10.1249/MSS.0b013e31817c7133

[23] Colley, R. C. and Tremblay, M. S. (2011). Moderate andvigorous physical activity intensity cut-points for the Actical accelerometer. Journal of Sports Sciences, 29, 783-789. doi:10.1080/02640414.2011.557744

[24] Wong, S., Colley, R. C., Connor-Gorber, S. and Tremblay, M. S. (2011). Accelerometer sedentary activity thresholds for adults. Journal of Physical Activity \& Health, 8, 587-591.

[25] Canadian Guidelines for Body Weight Classification in Adults. Catalogue Number: H49-179/2003E, 2003, Ottawa, Health Canada.

[26] Van Dyck, D., Deforche, B., Cardon, G. and De Bourdeaudhuij, I. (2009) Neighbourhood walkability and its particular importance for adults with a preference for passive transport. Health \& Place, 15, 496-504. http://dx.doi.org/10.1016/j.healthplace.2008.08.010

[27] Martin, S.L., Kirkner, G.J., Mayo, K., Matthews, C.E., Larry, J. and Hebert, J.R. (2005) Urban, rural, and regional variations in physical activity. The Journal of Rural Health, 21, 239-244. doi:10.1111/i.1748-0361.2005.tb00089.x

[28] Lebel, A., Pampalon, R., Hamel, D. and Theriault, M. (2009) The geography of overweight in Quebec: A multilevel perspective. Canadian Journal of Public Health, 100, 18-23.

[29] Parks, S.E., Housemann, R.A. and Brownson, R.C. (2003) Differential correlates of physical activity in urban and rural adults of various socioeconomic backgrounds in the United States. Journal of Epidemiology and Community Health, 57, 29-35. doi:10.1136/jech.57.1.29

[30] Van Dyck, D., Cardon, G., Deforche, B., Sallis, J.F., Owen, N. and De Bourdeaudhuij, I. (2010) Neighborhood SES and walkability are related to physical activity behavior in Belgian adults. Preventive Medicine, 50, S74-S79. doi:10.1016/j.ypmed.2009.07.027

[31] Van Dyck, D., Cardon, G., Deforche, B., Owen, N., Sallis, J.F. and de Bourdeaudhuij, I. (2010) Neighborhood walkability and sedentary rime in Belgian adults. American Journal of Preventive Medicine, 39, 25-32. doi10.1016/j.amepre.2010.03.004 